\title{
Power Quality Regulation Using Free Market Oriented Approach
}

\author{
Shiun Chen ${ }^{1}$, Jing Wang2, T. T. Lie ${ }^{3}$ \\ ${ }^{1}$ Serawak Energy, Kuching, Serawak, Malaysia \\ ${ }^{2}$ Energy Market Authority, Singapore \\ ${ }^{3}$ Department of Electrical and Electronic Engineering, Auckland University of Technology, Auckland, \\ New Zealand \\ Email: chenshiun@sarawakenergy.com.my, tlie@aut.ac.nz
}

Received May 2014

\begin{abstract}
Power quality is a compatibility issue between the supply systems and the connected loads. It is often considered as a customer-side problem as its significance depends primarily on the sensitivity of the affected equipment and its function. Improvement solutions are implemented by or on behalf of the customers only if the negative impact is causing great financial losses. However, as the reliance on electronic devices continues to increase unabatedly, the percentage of equipment being affected is expected to grow appreciably. In due course, the number of affected equipment could be so large that it is only practical and economical to implement universal solutions instead of individual solutions. This paper provides an early view of this scenario and explores the various elements necessary for reining in the poor power quality, widely expected to deteriorate further following deregulation of power industry. It attempts to use the free market oriented approach so that solutions implemented are justified on economical basis.
\end{abstract}

\section{Keywords}

Power Quality, Economic Evaluation, Energy Market, Deregulation

\section{Introduction}

Power quality is an umbrella concept for a multitude of power system disturbances [1] [2]. In a broad sense, any problem manifested in voltage, current or frequency deviation that results in failure or mis-operation of customer equipment can be regarded as a power quality problem. Power quality regulation therefore refers to how to provide a supply that is conducive to the connected loads. Technically, power supply system can only control the quality of voltage; it has no control over the current that a particular load may draw. Therefore, power quality standards are generally devoted to maintaining the supply voltage within certain limits [3] [4]. Although the many definitions of power quality in the literature and standards are not fully consistent with each other, but the phenomena considered are generally the same. In IEC 61000-2-1 [1], a thorough description of various power quality disturbances are categorized according to their typical duration, magnitude, and predominant frequency as over-voltage transients, voltage variations, voltage fluctuations, harmonic distortions, frequency variations 
and voltage imbalance.

Maintaining power quality can be viewed as a financial consideration instead of a solely technical problem [5]. Unless the phenomenon and the subsequent disruptions on equipment or process result in significant monetary losses, it may not be worthwhile to undertake any preventive or protective measures. This argument is further enhanced by the fact that not every piece of equipment is affected by the same power quality disturbances. In addition, similar equipment used for different purposes in different processes can have vastly different economic impacts when disrupted. The nature of the disturbance, the condition of the supplying network, the equipment's sensitivity or tolerance, and the importance of the equipment to the customers, all combine to provide an indicator for evaluating the severity of a power quality disturbance. Different customers are most likely to possess different importance levels and hence, under the spirit of deregulated market, they ought to be given the choice of differentiated power quality at different prices.

Therefore, it appears logical to employ market mechanism that has been widely adopted in the restructuring of power industry to regulate power quality. However, power quality encompasses many phenomena with distinct characteristics, making it difficult for one to agree on a generic definition. This perhaps causes each phenomenon to be treated separately and they are largely being managed in the same manner as before deregulation. This paper evaluates the potential of using market oriented approach in regulating power quality. It takes a conceptual view of the related issues, identifies the challenges that need to be overcome and studies the various issues that define how such free-market idea can be employed.

\section{Power Quality Regulation}

The expectation of electricity consumers has evolved over the past years, and has risen partly due to the extra publicities from the deregulation activities resulting in greater awareness, and better education [6]. This higher demand is nevertheless logical because the modern industrial processes with new types of electrical equipment are more adversely affected by poor power quality than the traditional equipment. In addition, integrated manufacturing supported by extensive automations and our today's individual way of life are more dependent on good quality of electricity than ever. All these can be narrowed to the ever-increasing use of semiconductor devices that have poorer tolerances towards power quality disturbances comparing to traditional equipment.

\subsection{Existing Approach}

There are many voltage quality regulations aiming to keep disturbance levels under certain limits that would allow all the electrical equipment connected to the grid to function properly [7]-[11]. Comparisons of different standards used in various countries were conducted for European countries [12] and Asia Pacific countries [13] [14]. The various regulation techniques were studied according to the categories of the voltage imperfections. For the surveys, it is clear that many countries have some form of voltage regulation, applied uniformly at the national level. Voltage quality is usually part of the national regulation, and EN50160 is often used as the regulation for low-voltage and medium-voltage levels in European countries. For higher voltage levels, only simple criteria such as frequency and voltage magnitude as specified in EN50160 are adopted.

However, there is no explicit standard for the majority of voltage quality phenomena. In EN50160, exact levels of compliance are stated for a few phenomena only. For most phenomena such as short duration variations, only indicative values are given. It is left to the users to define their own compatibility levels. There are harmonic limits defined in many countries but in some countries like Singapore, only frequency and long-duration voltage variations are regulated. Despite having these standards and regulations, no country imposes penalty for not meeting the regulations. Most utilities simply want to deliver a good product and therefore have committed to that. This commitment appears to continue even after deregulation. Likewise, there is no reward for good performance as there is no penalty for poor performance.

From the studies, it is observed that the regulation of power quality or voltage quality in most countries remains the same as before the industry is deregulated. The regulation and emission limits are set out of concern with system security and to achieve economical energy dispatch. The financial consequences of poor power quality are still not considered.

\subsection{Free-Market Approach}

The first challenge in employing free-market approach in regulating power quality is how to quantify it as a sel- 
lable entity. This requires some forms of definition that can differentiate a quality level from another, allowing different prices to be set to reflect its values. These definitions must allow the system quality level to be clearly linked to the tolerances of sensitive equipment, and perhaps the following financial impacts too. The system level is the basic or minimum level from which further improvement or correction measures can be implemented. It needs to be carefully chosen as a too pessimistic value (high level of quality) would lead to undue measures, higher costs and wastages since not all loads require such level. On the contrary, setting the value too low would result in poor quality causing many disruptions and making it necessary for many loads to install improvement or protection measures. In general, this value needs to be optimally chosen and set high enough to be deemed adequate by most electrical equipment without causing any cost overrun.

Power quality is an umbrella concept encompassing many electromagnetic phenomena. Each of them has distinct characteristics, causing different problems and requiring different solution too. It therefore appears complicated to produce a universal definition for grading power quality. One possible way of quantifying power quality levels is to consider each of the negative symptoms individually. More specifically, as the main intent of introducing free-market approach is to use economic signals in regulating power quality, this paper considers how various phenomena can be controlled and the associated costs. The various phenomena are therefore divided into two general groups of emission limit control and value added service mode of power quality management.

The former group accounts for phenomena that originate from customers and affect the quality of supply systems. It includes harmonic current emissions and randomly varying power demands from fluctuating loads like the arc furnaces. The solution would be primarily corrective in nature for polluting equipment, and the regulation would need to enforce certain limits on the customers. The latter group concerns the quality of supply voltage and accounts for disturbances like voltage dips, swells, interruptions, imbalances and distortions. These are largely considered as inadequacies in the supply system and the solution would generally be protective in nature for sensitive equipment. A minimum but acceptable quality level needs to be agreed upon between the customers and the power company.

In introducing free-market idea, monetary incentives or penalties are designed to deter emission in the former group. Each user can be prescribed a set of limits according to the power demand and the supply voltage level. Lower limits are enforced at high voltage levels as such pollutions have more wide-ranging influence over the entire network. The step-down transformers often act as a layer of separation between the system and disturbing loads. The penalty can be set according to the cost of cleaning up the emissions. For the latter group, economic signal is set to encourage investments in power quality improvement measures. However, there are two ways of determining the prices for different quality levels. One obvious way is to consider the cost of improvement measures, which tends to increase with power ratings of the protected loads. The second way is to set the price at the perceived "value" of the quality level, which depends on the economic consequence suffered by customers if no action is taken. This economic impact may vary significantly between different classes of customers, depending on how the affected equipment is used and its importance to the customer's business function. This determination may be possible for individual customers but would be irrelevant for the masses. A computer is expected to be more highly valued by a commercial customer using it for inventory control than a residential customer using it for casual exchanges with friends.

Previously, power networks were planned taking into account a certain level of expected power quality. But now, the base-rate regulation is being replaced by performance-based remuneration schemes in the liberalized environment. Unfortunately, these new schemes encourage reducing operating costs and trimming infrastructure investments. Many think that this will lead to deterioration of power quality. Hence, in such restructured environment, an incentive-based mechanism is necessary for power quality regulation. Separate markets for energy and reserve are already in operation and some are contemplating a reactive power market. Equally, a new market can be conjured to manage power quality and to prevent it from further deterioration. The following sections study the potential makeup of a power quality market and the associated pricing mechanism that is crucial for the success of the market.

\section{Power Quality Benefits and Costs}

To establish a market for power quality as a product or service, it must be made quantifiable so that the benefits and costs can be readily evaluated. The measurable quantity must enable decision to be made on whether or how 
much to invest in improvement solutions. Here, a quantity "Effectiveness" is introduced as measure of the amount of savings achieved by power quality improvement services. It is defined as the percentage of disturbances that can be prevented through the particular service. For example, 50\% Effectiveness means that with the improvement service, half of the disturbances that originally cause disruptions can now be prevented from causing any disruption. Obviously, $100 \%$ is the absolute limit for this Effectiveness. The benefit gained by the customers and the costs of improvement services are then defined according to the targeted level of Effectiveness.

This section shows the general shape and trend of the benefit and cost curves. These curves serve as foundation for determining the basic power quality level based on monetary basis.

\subsection{Customer Benefit Functions}

The customer's willingness to pay for improvement service depends on the potential benefits that the customer can gain from the service. This value is purely decided by the importance of the load and tends to vary from individual to individual. This value determines the demand from customers for the service in term of quantity and quality. There will always be some customers who value their loads more than the others. The customers with important load shall benefit more from the same service and consequently may be more willing to pay more for it. However, if a universal service is provided, customers with less important loads shall also benefit. The value of benefit that realized by these less important loads is expected to be smaller. Thus, as the power ratings of the improvement service increases, the unit benefit shall decrease with the total benefit increasing at a slower rate as shown in Figure 1. The $X_{1}$ and $X_{2}$ denote services of different quality levels (or Effectiveness) where $X_{1}$ is of a lower quality than $\mathrm{X}_{2}$.

Translating this to unit benefit function to represent how much one unit of improvement service can bring, the curves would be decreasing as shown in Figure 2. It is also piecewise as the different composition of loads entails different value for the same service in accordance to their nature of operation. In general, higher valued loads would be protected first. Hence, the curve starts with high values for this unit benefit and decreases subsequently. As the improvement device reaches its power ratings limit, a different device would be needed resulting in a discontinuity in the curve. It is only logical that the new device would be less effective (lower unit benefit value) and the protected loads are valued less (continued trend of decreasing unit benefit). If the unit benefit is defined as a monetary value, an equivalent price for the improvement service can be set on the curve. For example, for a price of $\mathrm{P}_{1}$, only a quantity $\mathrm{S}_{1}$ of load can only derive financial benefit from this service. Additional loads can only be protected if a lower cost service is available.

Assuming that each disruption causes a fixed amount of losses, the total benefit curve is then a linear function of the Effectiveness as follows,

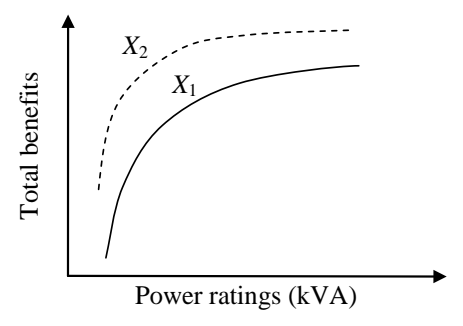

Figure 1. Customer benefits w.r.t. ratings of improvement solution.

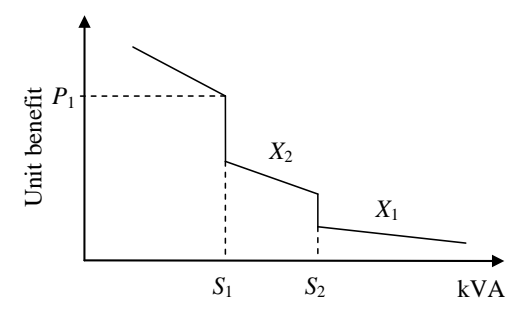

Figure 2. Customer unit benefit function. 
where

$$
\text { Benefit }=k \cdot N \cdot X
$$

$k$ is the aggregated loss of the customers due to one disruption;

$X$ is the Effectiveness of the service, the percentage of the mitigated voltage sags that falls within the tolerance curve of the loads;

$N$ is the original number of voltage sags beyond the tolerances of the loads.

It is obvious that the customer benefit would depend on the system performance and the equipment's Effectiveness. The variable $N$ representing the original sag performance and can be derived through measurements [15] or estimations [16].

With the eventual power quality determined by the Effectiveness chosen, the customer benefit is therefore directly proportional to the quality too. The benefit functions will be straight lines, increasing with the Effectiveness. An improvement service of higher power ratings would produce more benefit as it benefits more loads. However, the rate of increase would be slower as the unit benefit is expected to decrease with the power ratings as shown in Figure 3. In other word, the aggregated benefit $k$ per disruption becomes smaller when a larger volume of loads is being protected.

\subsection{Cost Functions of Improvement Services}

The cost of the service is dictated by the power conditioning equipment, the selection of which is subjected to the targeted Effectiveness and the power ratings of the protected loads. At the initial stage when the Effectiveness is low, only a modest cost is needed to mitigate the few minor disturbances. As the requirement rises, the cost would increase at an increasing rate or exponentially as mitigating more severe disturbances is expected to be more costly. Thus for a given power ratings, the total cost function shall exhibit an exponential-like characteristic as shown in Figure 4. It also varies with the power ratings. Basically, the unit cost is small when the Effectiveness requirement is low but increases gradually as the need becomes more stringent.

In addition, if considering the restriction from the technologies that are available to provide the improvement service, the cost function would be made up of several discrete lines with each line representing a specific technology. Figure 5 shows such a scenario with each ladder step representing a different technology. For power quality issues like voltage sags, a different technology may be needed to achieve a different Effectiveness of protection. Likewise, different curves would need to be constructed for different power ratings.

The cost of the power conditioning equipment usually varies with its power ratings as well as its Effectiveness. Naturally, it can be expected that for higher ratings, the cost would be higher as more energy needs to be stored to provide the service. In addition, the unit cost is also expected to change with the ratings. Although no definite

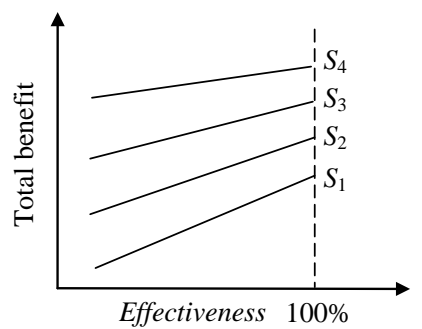

Figure 3. Customer benefit w.r.t. Effectiveness.

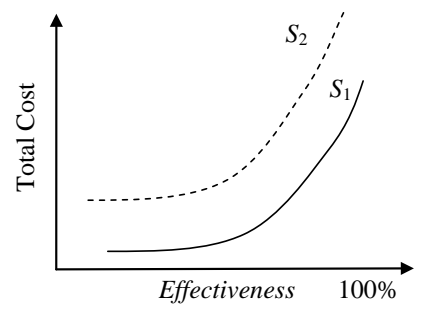

Figure 4. Total service cost w.r.t. Effectiveness. 


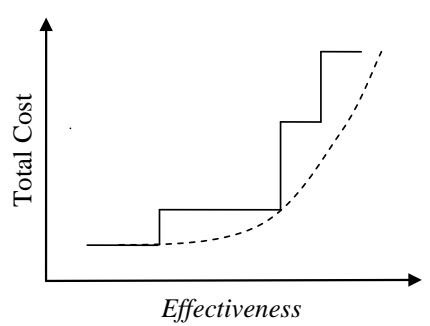

Figure 5. Ladder like service cost curve.

pattern of relationship between the unit cost and power ratings is found for each protection device, very different costs have been observed for some of them. From [5], the cost for each improvement device is given as unit cost per kVA. Hence, the cost function shall be generalized as the following,

$$
C=a_{i} \cdot S
$$

where

$i$ indicates different quality level in terms of type of equipment used or the Effectiveness of the solution $S$ is power ratings of the improvement service

At low ratings, the cost is dominated by some initial outlays related to the service installation. For a given quality or Effectiveness, the total cost shall increase exponentially with the power ratings. In Figure 6, several discrete lines represent the costs associated with different technologies (or different quality levels). The cost of improvement service increases linearly until a different technology is needed to accommodate the next higher power ratings.

\subsection{Cost-Benefit Optimization}

The main objective in carrying out cost-benefit analysis here is to determine a quality level that can satisfy both the customers' needs while keeping the cost in check. This requires determination of the service Effectiveness or quality and the power ratings or quantity needed. This in turn leads to the determination of the price. The decision can be made through a process of maximizing the net benefit that can be achieved through the selection of the right quality (Effectiveness) and quantity (power ratings) to be served.

For a given power ratings, the cost function exhibits an exponential-like curve. In Figure 7, it is drawn as a continuous curve assuming that the improvement device can be smoothly enhanced to raise its Effectiveness. A higher cost function is expected for higher power ratings. Assuming a fixed amount of losses per disruption and the number of disruptions is inversely proportional to the Effectiveness, the benefit curve would be a straight and increasing line. At higher power ratings, the benefit is expected to be higher but increasing at a lower rate with Effectiveness since the additional loads that are being protected would not be valued as highly as the more important loads that are protected earlier.

The quality and quantity to be provided shall be determined through a process of maximizing the net benefit that can be achieved through the selection of the right quality to be served. From this figure, the optimization process is to find the optimal power ratings (determining which pair of benefit and cost functions to use) and the optimal quality level (deciding the targeted Effectiveness of improvement service) where the difference between them is maximized. This would maximize the net benefit indicated as $\pi$ in the figure. The price of this level of power quality can then be determined from this Effectiveness level. At an aggregate load point, there are no separate lines available to offer different customers different quality service, then only a uniform quality can be delivered and the ratings of the load is fixed. Thus there is only one pair of cost and benefit curves, and the optimization is simplified to the determination of the optimal quality only.

In a "seller" market with limited option, the price would be $P_{1}$ with all the net benefit goes to the service supplier. On the other hand, in a "buyer" market where there are many service suppliers, a cost-based price of $P_{2}$ is expected to give all benefits to the customers. If the power quality market is centrally coordinated, the coordinator can choose to apportion this benefit between the customers and suppliers by picking a price between these two extremes such as $P_{3}$. Through this mechanism, appropriate values can be derived as the differentiated prices for different grades of power quality. 


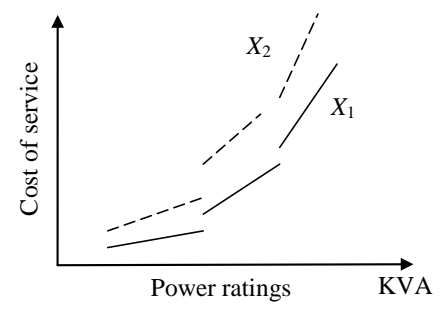

Figure 6. Service cost w.r.t. power ratings.

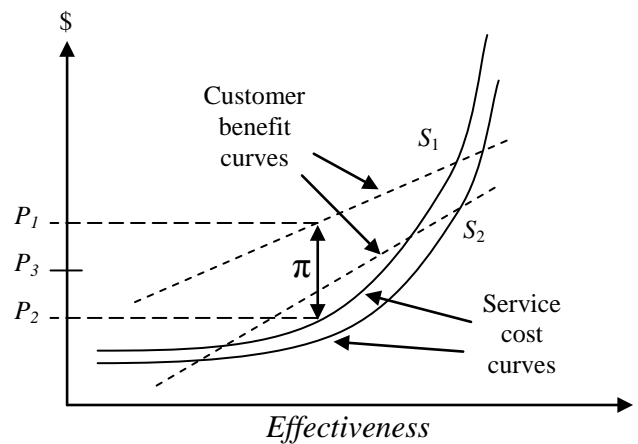

Figure 7. Customer benefits and power quality improvement service costs.

\section{Illustrative Examples}

Using the information provided in various literature [5], [15] and [16], the following example show how the optimal quality and quantity of improvement service can be determined. Three types of the power conditioning equipment are used here to denote the different levels of Effectiveness. They are the DVR (Dynamic Voltage Restorer), flywheel ride-through devices and the UPS (Uninterruptible Power Supply) as a battery-based ridethrough method. Their costs for different sizes are given in Table 1 [5].

Here, the illustration is shown for loads that are between $2-10$ MVA. The cost function is a piecewise ladder curve as shown in Figure 8. For loads with other power ratings, similar procedure can be undertaken and the resulted net benefits are compared across measures using improvement service of different power ratings.

The cost of disruption indirectly defines the benefit that can be achieved from carrying out the improvement service. This cost can be derived from those defined for interruptions and is used to indicate the impacts of the disruption on different customers, as shown in the Table 2.

The system sag performance from the EPRI survey [15] is then used as the basic level of quality that can be expected from the distribution system as shown in Table 3. With this system performance, there are a significant number of disruptions expected by the ITIC complaint loads. Therefore, improvement service can be contemplated and justified not only technically but also economically.

With this system performance and the loads are ITIC compliance, the number of disruptions due to voltage sags beyond the load tolerance is 23.207 times. Using this information, the customer benefit can be calculated since the cost a single disruption causes is known. The benefit shall be the avoided loss after the protection service is implemented. The customer benefit shall be linear to the Effectiveness of the improvement equipment. Figure 9 shows the benefit curves for different categories of customers and they are assessed against the costs of the improvement options.

From the Figure 9 and Figure 10, the optimal quality of service can be determined by finding the optimal quality level (Effectiveness) where net benefit is maximized. This is when the difference between the benefit curve and the cost curve is at the greatest. For the commercial and industrial customers, the net benefit is maximized for selecting UPS as the protection measure. On the other hand, for the residential customers, flywheel ride-through provides higher economical net benefit even though it is less effective than UPS. This is because residential loads are not valued as much as those of commercial and industrial customers. Hence, it is not economically worthwhile to apply the higher-cost UPS protection. 
Table 1. Cost of improvement services.

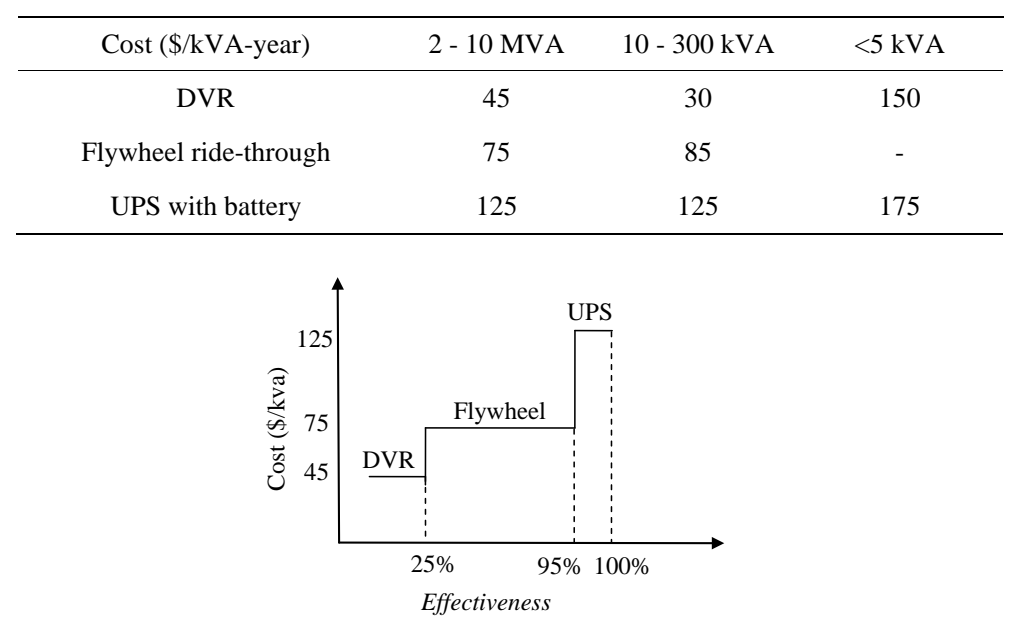

Figure 8. Cost function w.r.t. Effectiveness within 2 - 10 MVA range.

Table 2. Customer benefits.

\begin{tabular}{cc}
\hline & Benefit $(\$ / \mathrm{kw})$ per disruption \\
\hline Commercial & 125 \\
Industry & 80 \\
Residential & 15 \\
\hline
\end{tabular}

Table 3. Sag density table from EPRI survey.

\begin{tabular}{cccccccc}
\hline Magnitude & $0.00-0.02 \mathrm{~s}$ & $0.02-0.05 \mathrm{~s}$ & $0.05-0.20 \mathrm{~s}$ & $0.20-0.40 \mathrm{~s}$ & $0.40-0.60 \mathrm{~s}$ & $0.60-0.80 \mathrm{~s}$ & $>0.8 \mathrm{~s}$ \\
\hline $90 \%-100 \%$ & 0 & 0 & 0 & 0 & 0 & 0 & 0 \\
$80 \%-90 \%$ & 4.22 & 6.33 & 12.683 & 6.4 & 1.367 & 0.666 & 0.067 \\
$70 \%-80 \%$ & 2.92 & 4.38 & 8.817 & 4.55 & 0.933 & 0.434 & 0.033 \\
$60 \%-70 \%$ & 0.439 & 0.657 & 1.388 & 0.875 & 0.116 & 0.167 & 0 \\
$50 \%-60 \%$ & 0.437 & 0.658 & 1.387 & 0.875 & 0.117 & 0.167 & 0 \\
$40 \%-50 \%$ & 0.439 & 0.6575 & 1.3875 & 0.875 & 0.117 & 0.166 & 0 \\
$30 \%-40 \%$ & 0.108 & 0.1625 & 0.7795 & 0.375 & 0 & 0.2 & 0 \\
$20 \%-30 \%$ & 0.109 & 0.162 & 0.679 & 0.375 & 0.1 & 0.2 & 0 \\
$10 \%-20 \%$ & 0.108 & 0.163 & 0.729 & 0.375 & 0.05 & 0.2 & 0 \\
$0 \%-10 \%$ & 0.52 & 0.78 & 0.525 & 0.675 & 0.5 & 3.4 & 1.7 \\
\hline
\end{tabular}

For the RBTS system, disruption to loads sensitive to voltage sags beyond the ITIC tolerance is much smaller at 2.322, with the system performance as summarized in Table 4. Therefore, the impact of the improvement services is generally small. Only for some very important loads like those belonging to the commercial and industrial customers, the flywheel ride-through protection is good enough to achieve the maximum net benefit. For residential customers, there is no need to apply any protection since the system performance is already adequate according to the lower values of the loads. In fact, it is not worthwhile to apply UPS for any load since the existing system performance is already very good.

The above examples using EPRI survey data and RBTS simulation data are summarized in the following Table 5, Table 6. The underlined figures indicate the solution with the highest net benefit. 


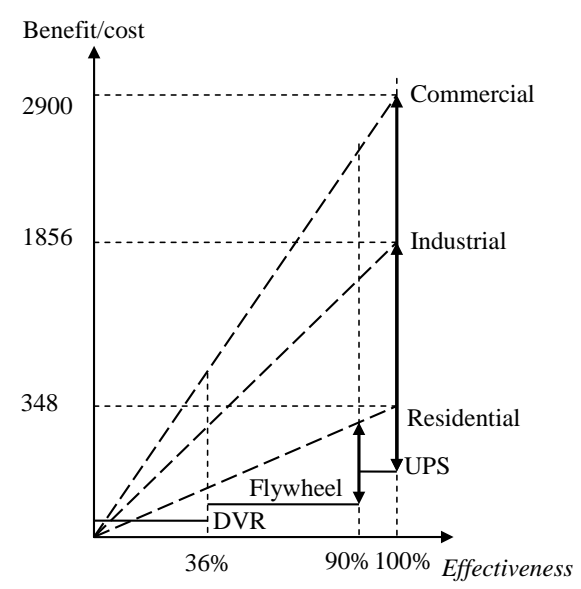

Figure 9. Benefit-cost analysis using EPRI survey data.

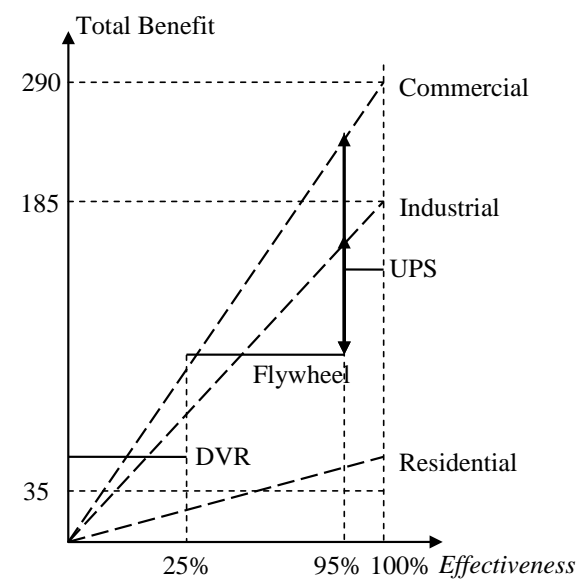

Figure 10. Cost benefit analysis for RBTS system.

Table 4. Sag density table for RBTS system.

\begin{tabular}{ccccccc}
\hline Magnitude & $0.00-0.05 \mathrm{~s}$ & $0.05-0.20 \mathrm{~s}$ & $0.20-0.40 \mathrm{~s}$ & $0.40-0.60 \mathrm{~s}$ & $0.60-0.80 \mathrm{~s}$ & $>0.8 \mathrm{~s}$ \\
\hline $90 \%-100 \%$ & 0 & 0.471 & 0.073 & 0.088 & 0 & 0.192 \\
$80 \%-90 \%$ & 0 & 0.011 & 0 & 0 & 0 & 0.016 \\
$70 \%-80 \%$ & 0 & 0.035 & 0.007 & 0.008 & 0 & 0.003 \\
$60 \%-70 \%$ & 0 & 0.020 & 0.006 & 0.002 & 0 & 0 \\
$50 \%-60 \%$ & 0 & 0.187 & 0.017 & 0.009 & 0 & 0.019 \\
$40 \%-50 \%$ & 0 & 0.422 & 0.139 & 0.084 & 0 & 0.020 \\
$30 \%-40 \%$ & 0 & 0.318 & 0.018 & 0.120 & 0 & 0.095 \\
$20 \%-30 \%$ & 0 & 0.207 & 0 & 0.003 & 0 & 0.161 \\
$10 \%-20 \%$ & 0 & 0.008 & 0 & 0 & 0 & 0.101 \\
$0 \%-10 \%$ & 0 & 0.110 & 0.097 & 0 & 0 & 0.132 \\
\hline
\end{tabular}

\section{Pricing Strategy and Benefit Allocation}

By maximizing the net benefit as described above, the optimal quality of service can be delivered. The price of the service shall determine how this net benefit is allocated between the supplier and the customers. In the process of determine the optimal service quality; it is assumed that the customers are willing to take up any service 
that can bring more benefit than the price they have to pay. For the benefit function defined with respect to quantity, the unit benefit of the customers with respect to quantity can be obtained by simply taking the derivative of the total benefit function. And this function can be utilized as the demand function of the customers' willingness to pay for the service.

As described earlier, customers can be categorized into three major groups of commercial, industrial and residential, very much according to the sensitivity of their load equipment and importance. Consequently, the customer demand function for improvement service would be expected to demonstrate different elasticity due to the different composition of loads among them. However, to facilitate the study here, the demand function is taken to be linear over certain range of quality and quantity of power quality improvement service. This assumption enables the demand curve to be described as:

where

$$
P=P^{\max }-\varepsilon \cdot S
$$

$S$ is power ratings of the customer load to be provided with power quality improvement service;

$\varepsilon$ stands for the elasticity.

These relationships can be demonstrated in the following Figure 11. MR is the marginal revenue (or benefit) while MC is marginal cost of the improvement service. $P^{*}$ and $S^{*}$ indicate the selling price and quantity where the profit of the supplier can be maximized. The profit earned by the supplier is indicated by the area of $P^{*} \mathrm{BAP} P^{* *}$.

From the perspective of overall social economic benefits, the supply of power quality service should be provided as long as the price is higher than the marginal cost of the service. Then, the social welfare is indicated by the area of $\mathrm{DP} P^{* *} \mathrm{E}$. With the current supply quantity $S^{*}$, the area of $\mathrm{DB} P^{*}$ indicates the customer surplus or benefit enjoyed by the customers. The area of $P^{*} \mathrm{BA} P^{* *}$ indicates the consumer surplus transferred to the firm providing the service. The area of BEA indicates the potential consumer surplus that has not being tapped when providing only $S^{*}$ amount of service. The existence of such loss shows that economic efficiency has not been fully achieved. This loss should be minimized in order to maximize the overall benefit. In this case, the supply

Table 5. Summary of performance with EPRI survey data.

\begin{tabular}{ccccccc}
\hline & \multicolumn{3}{c}{ Total customer benefits (\$) } & \multicolumn{3}{c}{ Maximum net benefit $\pi(\$)$} \\
\cline { 2 - 7 } & DVR & Flywheel & UPS & DVR & Flywheel & UPS \\
\hline Commercial & 1097.99 & 2616.63 & 2900.88 & 1052.99 & 2541.63 & $\underline{2775.875}$ \\
Industrial & 702.71 & 1674.64 & 1856.56 & 657.71 & 1599.64 & $\underline{1731.56}$ \\
Residential & 131.7585 & 313.995 & 348.105 & 86.7585 & $\underline{238.995}$ & 223.105 \\
\hline
\end{tabular}

Table 6. Summary of performance with RBTS Simulation data.

\begin{tabular}{ccccccc}
\hline & \multicolumn{3}{c}{ Total customer benefits (\$) } & \multicolumn{4}{c}{ Maximum net benefit $\pi(\$)$} \\
\cline { 2 - 7 } & DVR & Flywheel & UPS & DVR & Flywheel & UPS \\
\hline Commercial & 74.93 & 277.47 & 290.17 & 29.93 & $\underline{202.47}$ & 165.17 \\
Industrial & 47.96 & 177.58 & 185.71 & 2.96 & $\underline{102.58}$ & 60.71 \\
Residential & 8.99 & 33.30 & 34.82 & -36.01 & -41.70 & -90.18 \\
\hline
\end{tabular}

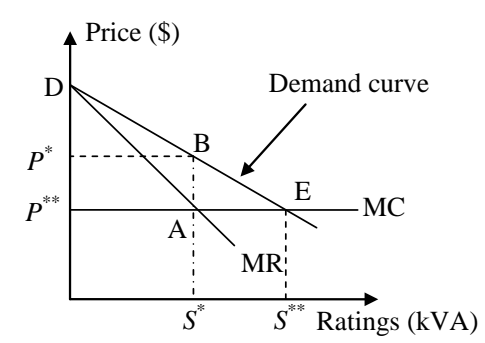

Figure 11. Marginal benefit and cost of PQ improvement service. 
quantity should be traded at the $S^{* *}$. This can then lead to two possible outcomes. One is to set one uniform price at the marginal cost $P^{* *}$, which is the situation with perfect competition, and the entire surplus goes to the customer. The other is to practice price discrimination which is to set more than one price with the lowest one at $P^{* *}$ so that the selling quantity of $S^{* *}$ can be realized.

\subsection{Differentiated Pricing}

As shown in Figure 12, by setting up a series of different prices and ratings to customers, the supplier can achieve greater profit by selling more products at price above the average cost. Through this, more of the consumer surplus is transferred to the firm. To implement differentiated pricing, it is necessary to find out the demand curves for each category of the customers.

Under a monopolistic condition, the service provider is able to practice perfect price discrimination by charging different prices so that the entire consumer surplus goes to the firm. However, considering the practical constraints, it is impossible to implement perfect price discrimination over all customers. Partial price differentiation may be possible since customers of different nature exhibit different sensitivity to the power quality disturbances. Different tariffs can be set for each category of customers, although essentially, they can all be protected using the same type of power conditioning equipment. If the provider can offer different degrees of guarantee to different customers, maximum benefits to all can be determined using the following formulation.

$$
\text { MaxBenefit }=\max \sum \rho_{j} d_{j}-\sum_{k} r_{k} \sum_{j} d_{k j}
$$

where

$\rho_{j}$ is the tariff charge with PQ service for a consumer category;

$r_{k}$ is the average cost per power unit, which shall include fixed and variable costs, at different load points;

$d_{k j}$ is the consumption of power quality service by a category of consumer at each load point.

\subsection{Influence of Government Activity}

The above optimization is undertaken from the investor's point of view. The power quality market regulator can still exert influence by setting price caps. From the regulator's viewpoint, the objective is to achieve the overall social economic welfare. Especially in a public utility business such as the power utility, regulator often does not allow the company to take all the benefits. There must be some sort of regulations to prevent a monopoly firm from exploiting the customers.

As discussed above, the economic efficiency can be fully achieved when the price is equal to the marginal cost. This is basically marginal pricing. To implement multiple tariffs, the low-price takers can be offered with marginal price and at the efficiency that can best be achieved. However, there is still the possibility that the monopoly firm can still exploit those more affordable consumers through fixing of high prices.

Another approach is through the rate of return regulation. This rate of return regulation is a traditional framework to define the macro-economic performance of regulated companies. The regulator can devise the monopoly pricing schemes by setting a fair rate of return on investment. An appropriate rate of return can give the firm the right incentives to minimize cost and the resulted price will give both the consumer and the firm equitable benefits.

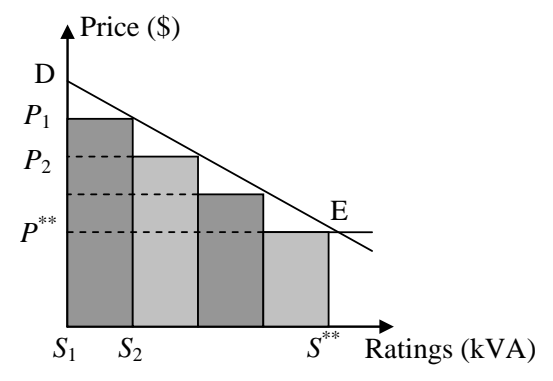

Figure 12. Differentiated pricing mechanism. 


\section{Conclusion}

Power quality problems are often regarded as financial considerations in addition to solving the technical issues. A free-market approach where monetary returns take precedence would be a natural choice for regulating power quality. Unless the benefits gained by the customers is higher than or equal to the price, there will not be a market for such quality level. Similarly, unless suppliers can achieve a price higher than the cost of improvement measures, there will not be any such services offered to the customers. To make use of market signals as incentives for investments in power quality improvement, a power quality market needs to be established. Different grades of power quality are to be defined and set at differentiated prices. Choosing the power quality grades and setting of the corresponding prices need to compare the customer benefits against the costs of the improvement services. Once the quality levels are chosen, the prices can be fixed by apportioning the marginal benefits between the customers and the service suppliers. Although the monetary aspect of power quality regulation can be resolved by introducing a dedicated market with proper pricing mechanism, there remains many technical challenges such as how to deliver different grades of power quality over a common distribution system.

\section{References}

[1] IEC 61000-2-1 (1990) Electromagnetic Compatibility (EMC)-Part 2-1: Environment-Description of the Environment-Electromagnetic Environment for Low-Frequency Conducted Disturbances and Signalling in Public Power Supply Systems. 1st Edition.

[2] IEEE Std. 1159-1995 (1995) IEEE Recommended Practice for Monitoring Electric Power Quality.

[3] Dugan, R.C. (2003) Electrical Power Systems Quality. 2nd Edition, McGraw-Hill, New York.

[4] Arrillaga, J., Watson, N.R. and Chen, S. (2000) Power System Quality Assessment. John Wiley \& Sons, New York.

[5] McGranaghan, M. and Roettger, B. (2002) Economic Evaluation of Power Quality. IEEE Power Engineering Review, 22, 8-12.

[6] Shahidehpour, M. and Alomoush, M. (2002) Restructured Electrical Power Systems: Operation, Trading, and Volatility. Marcel Dekker, Inc., New York.

[7] BS EN 50160 (2000) Voltage Characteristics of Electricity Supplied by Public Distribution Systems.

[8] IEC 61000-2-2 (2002) Electromagnetic Compatibility (EMC)—Part 2-2: Environment-Compatibility Levels for LowFrequency Conducted Disturbances and Signaling in Public Low-Voltage Power Supply Systems.

[9] IEC 61000-2-4 (2002) Electromagnetic compatibility (EMC)—Part 2-4: Environment-Compatibility Levels in Industrial Plants for Low-Frequency Conducted Disturbances.

[10] IEC 61000-3-2 ed. 2 (2000) Electromagnetic compatibility (EMC) —Part 3-2: Limits-Limits for Harmonic Current Emission (Equipment Input Current up to and Including 16 A per Phase).

[11] IEEE Std. 519-2002 (2002) IEEE Standard Practices and Requirements for Harmonic Control in Electrical Power Systems.

[12] (2001) Quality of Electricity Supply: Initial Benchmarking on Actual Levels, Standards and Regulatory Strategies. Council of European Energy Regulators.

[13] (2001) Electricity Distribution Code. Office of the Regulator-General, Victoria.

[14] (2002) Singapore Electricity Market Rules, Energy Market Authority.

[15] Gunther, E.W. and Mehta, H. (1995) A Survey of Distribution System Power Quality-Preliminary Results. IEEE Transaction on Power Delivery, 10, 322-329.

[16] Wang, J., Chen, S. and Lie, T.T. (2007) A Systematic Approach for Evaluating Economic Impact of Voltage Dips. Electric Power Systems Research, 77, 145-154. 